\title{
Bowel injury: a rare but dreaded complication of unsafe abortion
}

\author{
Monika Ramola ${ }^{1} *$, Priyanka Chaudhari ${ }^{1}$, Parul Singh $^{2}$, Mahesh Ramola $^{3}$
}

\author{
${ }^{1}$ Department of Obstetrics and Gynaecology, SGRRIMHS, Dehradun, Uttarakhand, India \\ ${ }^{2}$ Department of Obstetrics and Gynaecology, PGIMS, Rohtak, Haryana, India \\ ${ }^{3}$ Department of Surgery, SGRRIMHS, Dehradun, Uttarakhand, India
}

Received: 01 July 2016

Accepted: 05 August 2016

\author{
*Correspondence: \\ Dr. Monika Ramola, \\ E-mail: dr.monika.ms@gmail.com
}

Copyright: (c) the author(s), publisher and licensee Medip Academy. This is an open-access article distributed under the terms of the Creative Commons Attribution Non-Commercial License, which permits unrestricted non-commercial use, distribution, and reproduction in any medium, provided the original work is properly cited.

\begin{abstract}
Unsafe abortions represent a preventable yet major cause of maternal mortality and morbidity in India. Intestinal perforation is a rare dreaded complication of unsafe abortion. It is commonly seen in countries in which abortions are performed by people without proper training and proper instruments. Bowel perforation occurs when the posterior vaginal wall or the uterine wall is perforated. The ileum and the sigmoid colon are the most commonly injured portion of the bowel. Here, we report a case of ileal perforation following induced unsafe abortion which was managed successfully.
\end{abstract}

Keywords: Bowel injury, Unsafe abortions

\section{INTRODUCTION}

Unsafe abortion is one of the most neglected sexual and reproductive health problems in India. It is defined as an induced abortion process conducted either by unskilled personnel or performed in anon accreidated facility. ${ }^{1}$ The most common reasons for induced abortion are unwanted pregnancy, health problems, want of a male child, economic, social or family problems that forced the women to seek abortion. Bowel perforation is a rare but serious complication of induced abortion. These injuries often go unnoticed and unrecognized by the unqualified person further delaying their proper management, hence leading to catastrophic morbid situation to the mother.

\section{CASE REPORT}

A 29 year old woman P2L2 with history of previous 2 LSCS presented to the emergency with complains of fever off and on, lower abdominal pain and abdominal distension of five days duration. After about $48 \mathrm{hrs}$, she noticed passage of loose stools from the vagina two to three times per day. She underwent termination of pregnancy twice at a peripheral private centre for? Three and a half months amenorrhea. No documented record of the procedure was traceable. First procedure was ten days back following which she complained of persistent vaginal bleeding for which she consulted same private centre and then again underwent same procedure after five days which lead to complications. On examination at our centre, she was conscious, oriented, febrile, pulse rate was $100 / \mathrm{min}$ and $\mathrm{BP}$ was $100 / 60 \mathrm{~mm} \mathrm{Hg}$. Per abdominal examination, showed that abdomen is distended and there was generalized tenderness, guarding and rigidity. Bowel sounds were sluggish. Per speculum examination revealed stools coming out through the cervical os, vaginal walls were intact. On per vaginal examination uterine size could not be accessed because of tenderness. After proper work up and routine investigations including CT scan, patient was taken for laparotomy .Per op findings revealed, a rent of the size $3 \times 3 \mathrm{~cm}$ in the fundus of the uterus through which ileum was seen going into the cavity as shown in Figure 1. On removing the bowel from the uterine rent, the bowel segment was found to be gangrenous. Proximal bowel was distended uptil the ileum as shown in Figure 2. Thorough lavage was done and gangrenous segment was resected and a double barrel ileostomy was performed. Uterine rent was repaired in two layers with vicryl no 1 and check curettage was done through the rent. Patient was discharged in stable 
condition with end ileostomy. She was to follow up after six weeks for further management.

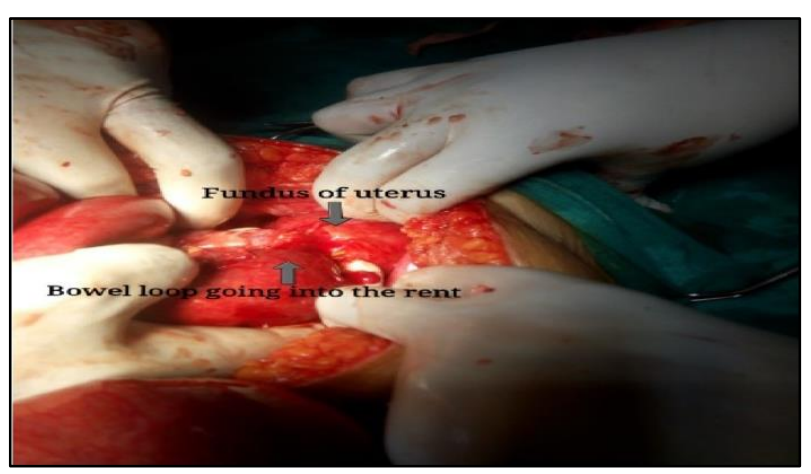

Figure 1: Per op site of uterine perforation.

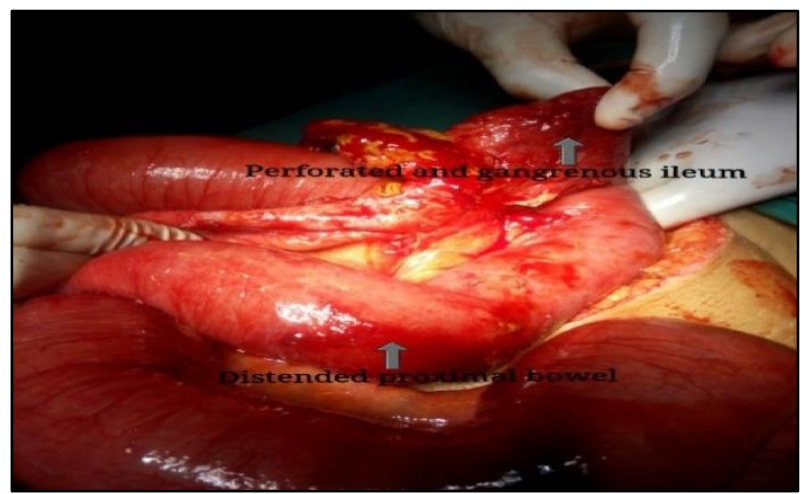

Figure 2: Per op gangrenous bowel.

\section{DISCUSSION}

Around 50 million women seek abortions yearly worldwide, out of which 20 million are unsafe. According to WHO, every 8 minutes a women dies due to complication from unsafe abortion making it one of the leading causes of maternal mortality $(13 \%)$. $^{2}$ Inspite of the revised MTP act in India still so many seek unsafe abortions which are performed by untrained personnels usually lady health visitors, untrained birth attendents and nurses in an unsterile environment with subsequent high risk of hemorrhage, infection and injury to the genital, urinary and GI tract. Apart from the mortality, many more are left with the stigmata of abortions such as infertility, chronic pelvic pain, bladder and bowel injury. Intestinal injuries have been reported in $5-18 \%$ cases in different studies. ${ }^{3,4}$ The bowel may be injured with uterine curette, ovum forceps, uterine sound or even plastic cannula when the posterior vaginal wall or the uterine wall is perforated. ${ }^{5}$ Ileum and the sigmoid colon are the most commonly injured portions due to their anatomical location. ${ }^{6,7}$ In this case, probably the ileum got injured while being caught in the fundus of the uterus in an attempt to pull the products of conception. That portion of the ileum became gangrenous. The patient presented with features of obstruction and ileouterine fistula. CT scan is the investigation of choice in diagnosing such conditions.
Early surgical intervention is the treatment option of choice. But most cases present late with features of peritonitis and sepsis. If presented earlier within the first 24 hours when there is minimal contamination, treatment option of ileal perforation is primary repair after thorough cleansing, washing and refreshening of the margins. If presented late, ileostomy is the treatment as was done in this case. Later on patient had to undergo ileostomy closure and reanastomosis of proximal and distal segments. Poor socioeconomic status, curettage done by unqualified persons, lack of specialist centres and doctors in rural areas, reluctance and hesitancy of both the parents family and abortionist, delayed referral due to unrecognized injury, these complications go unrecognized and lead to higher mortality and morbidity. ${ }^{8,9}$ Late presentations have a more protracted stay and poorer outcome.

\section{CONCLUSION}

Illegal abortions still outnumber the legal ones. Midtrimester abortions need an empathetic approach by trained doctors who usually discourage this procedure. This leads the patient to seek unsafe abortion from unqualified and uneducated personels. Complications like instestinal injuries are one of the dreadest complication. Early recognization of the injury, aggressive resuscitation and early surgical intervention is of paramount importance if morbidity and mortality is to be reduced in intestinal injury. Appropriate measures like easy accessibility of the health services when needed, increased surveillance on all unauthorized personnels involved in abortion, education programmes of family planning can help prevent unwanted pregnancies thus reducing unsafe abortion. There is a need to spread information, awareness and education among masses about the importance of safe abortions.

\section{Funding: No funding sources \\ Conflict of interest: None declared \\ Ethical approval: Not required}

\section{REFERENCES}

1. Bhattacharyya SK, Saha SP, Bhattacharya S, Pal R. Consequences of unsafe abortion in India; a casereport. Proc Obstet Gynaecol. 2011;2(2):4.

2. Khan S, Wojdyla D, Say L, Gulmezoglu AM, Van Look PF.WHO analysis of causes of maternal death: a systematic review. Lancet. 2006;367(9516):106674.

3. Jain V Unsafe abortion: a neglected tragedy. Review from a tertiary care hospital in India. J Obstet Gynaecol. 2004;7(3):197-201.

4. Rana A, Pradhan N, Gurung G, Singh M. Induced septic abortion:a major factor in maternal mortality and morbidity. J ObstetGynaecol Res. 2004;7(1):3-8.

5. Coffman S. Bowel injury as a complication of induced abortion. Am J Surg. 2001;7(10):924-26. 
6. Gludiran OO, Okonofua FE. Morbidity and mortality from bowel injury secondary to induced abortion. Af J Reprod Health. 2003;7(3):65-8.

7. Osmie U. Intestinal injury following induced abortion. Areport of 4 cases. Nig Med J. 1978;7(4):378-80.
8. Hodoro S, Conendant R. Prevention of unsafe abortion in Countries of Central Eastern Europe and Central Asia. Int J Gynaecol Obstet .2010:110.

9. Kinaro J, Ali TE, Schlangen R, Mack J. Unsafe abortion and abortion care in Khartoum, Sudan. Reprod Health Matters. 2009;17(34):71-7.

Cite this article as: Ramola M, Chaudhari $\mathrm{P}$, Singh P, Ramola M. Bowel injury: a rare but dreaded complication of unsafe abortion. Int $\mathbf{J}$ Reprod Contracept Obstet Gynecol 2016;5:3223-5. 